\title{
POLÍTICA URBANA E INCREMENTO DA RECEITA MUNICIPAL: novos desafios do gestor público
}

\author{
Maurício Soares de Sousa Nogueira ${ }^{1}$ \\ Jussara Maria Moreno Jacintho²
}

RESUMO: Pode o Imposto Predial e Territorial Urbano (IPTU) induzir o cumprimento da função social da propriedade? Ou não? E como? Utiliza-se o IPTU por seu importante aspecto distributivo, de difícil sonegação e que admite legalmente a progressividade das alíquotas. Metodologicamente, a partir de aspectos dogmáticos, normativos e de dados concretos; se analisa o município de Aracaju. O comportamento dúbio do IPTU e a sua estrutura regressiva, com os contribuintes mais pobres sofrendo tributação maior, destaca nos resultados. A melhoria da progressividade do sistema tributário pode contribuir na superação da elevada desigualdade de patrimônio e renda do Brasil.

Palavras-chave: Desigualdades. IPTU. Aspectos distributivos. Justiça. Tributário.

\section{URBAN POLICY AND INCREASE IN THE MUNICIPAL INCOME: new challenges of the public manager}

\begin{abstract}
Can the Urban Land and Territorial Tax (IPTU) the social function of property's fulfillment? Or not? And how? The IPTU is used because of its important distributive aspect, difficult to evade and that legally allows the progressivity of the aliquots. Methodologically, based on dogmatic, normative and concrete data aspects, the municipality of Aracaju has been analyzed. The dubious behavior of the IPTU and its regressive structure, with the poorest taxpayers suffering a greater taxation are highlighted at the results. The improvement of the the progressivity of the tax system can contribute to overcoming Brazil's high inequality of wealth and income.
\end{abstract}

Keywords: Inequalities. IPTU. Distributive aspects. Justice. Tax department.

\footnotetext{
${ }^{1}$ Mestrando na Universidade Federal de Sergipe e com MBA em Direito Tributário pela Fundação Getúlio Vargas. Jussara Maria Moreno Jacintho

${ }^{2}$ É doutora em Direito Constitucional, pela PUC/SP ( 2003) ,mestrado em Direito da Cidade pela Universidade do Estado do Rio de Janeiro (1996),especialização em Direito Civil pela FGV/RJ, e é graduada em Direito pela Universidade Federal de Sergipe (1988) . Atualmente é professora adjunta de direito consttucional e de Direito Urbanístico do Departamento de Direito da Universidade Federal de Sergipe. É professora do Mestrado em Direito da UFS, assim como do mestrado profissional em Administração Pública - Rede Profiap.
}

Revista de Direito Tributário e Financeiro | e-ISSN: 2526-0138 | Salvador | v. 4 | n. 1 | p. 69 -84 | Jan/Jun. 2018 


\section{Introdução}

Inicialmente vamos retomar o conceito de cidade preconizada pela Constituição Federal (CF) de 1988: cidade, no Brasil, é a sede administrativa do município. Em outras definições cidade é aquela que tem atividade econômica própria e congrega diversos tipos de serviços, gerando um comércio de bens e serviços específicos; não apenas aquela que agrega uma população. Como se pode perceber, nenhum dos dois conceitos exige uma determinada quantidade de pessoas para que uma aglomeração humana possa ser considerada uma cidade. Ponderando essa concepção, o Brasil, em que pese ter oficialmente (segundo os dados da Pesquisa Nacional por Amostra de Domicílios -PNAD- 2015) ${ }^{3}$ algo em torno de 84,72\% (oitenta e quatro vírgula setenta e dois por cento) de sua população concentrada em centros urbanos e 15,28\% (quinze vírgula vinte e oito por cento) nas zonas rurais; tem menos população urbana do que trazem os dados oficiais, haja vista que a definição do conceito de espaço urbano não se faz apenas a partir do comando legal (cidade é sede do município), indo além da configuração topográfica da cidade para encontrar um espaço que é construído coletivamente, sendo

Aquele que foge das cercanias da quadra e envereda as ruas, os pátios, as praças, além de outras localidades do meio urbano público. Trata-se de um espaço externo ao lote, que é vivenciado individualmente e coletivamente, espaços de encontros, de trocas de ideias e olhares. (COSTA, Ana Maria, 2014, p. 169).

Vale dizer que a definição do que é urbano não se faz apenas a partir de suas fronteiras geográficas, nem do seu papel jurídico-institucional, mas do tipo de relações sociais, econômicas, políticas e culturais, relações humanas, enfim, que se desenvolvem naquele espaço geográfico. Essa é a ponderada crítica feita por José Eli da Veiga, para quem o Brasil permanece vinculado ao aspecto formal ditado pelo Decreto-Lei n. 311 de 1938, em cujo artigo $3^{\circ}$ estabelece que a sede do município tem a categoria de cidade e lhe dá o nome e ainda.

Fora daqui não se usa critério administrativo para definir cidade. O mais comum é uma combinação de critérios estruturais e funcionais. Critérios estruturais são, por exemplo, a localização, o número de habitantes, de eleitores, de moradias, ou, sobretudo, a

\footnotetext{
${ }^{3}$ POPULAÇÃO rural e urbana. Portal IBGE Educa. Disponível em: < $\underline{\text { https://educa.ibge.gov.br/jovens/conheca-o- }}$ brasil/populacao/18313-populacao-rural-e-urbana.html $>$. Acesso em: 27 de junho, 2018.
}

Revista de Direito Tributário e Financeiro | e-ISSN: 2526-0138 | Salvador | v. 4 | n. 1 | p. 69 -84 | Jan/Jun. 2018 
densidade demográfica. Critério funcional é a existência de serviços indispensáveis à urbe (VEIGA, 2004, p. 28).

A partir dessa definição, os dados oficiais brasileiros, ao afirmar que a população urbana brasileira cresceu, desconsideram não apenas que as relações econômicas que ali se estabelecem não são as tipicamente urbanas, mas aquelas ainda com forte vinculação à cultura agrícola, com um contingente enorme de cidades (sedes de municípios) que nada produzem; bens ou serviços que possam ser ofertados em um mercado de trocas, estabelecido na própria cidade, assim como exclui de qualquer consideração que uma cidade só pode existir com bens e equipamentos urbanos disponíveis à população, tais como escola, hospital, farmácia, praças e parques etc, (o chamado critério funcional), sem os quais não há como realizar as denominadas "funções sociais” da cidade.

Pese o apego à formula jurídico-administrativa para conceituar a cidade, na perspectiva constitucional, a cidade e as suas implicações se destacam da regulação acerca do município. Há um município que recebe todo um tratamento, como ente da administração pública que é, autônoma político-administrativo-financeira e tributariamente. Mas há, sobretudo, uma regulação sobre a cidade, como espaço público projetado, como meio ambiente artificial ${ }^{4}$, porquanto construído, destacado da regulação sobre o município. A CF, enfim, reconhece que o viver na cidade, o sentido do urbano, não é pautado, necessariamente, pelas mesmas necessidades referentes ao município (veja-se como comprovação a contradição gerada involuntariamente pelo próprio texto constitucional, que assegura a repartição das receitas tributárias como medida consagradora do pacto federativo). Desta forma, ela repassa a competência material dos serviços públicos afetos à comunidade local, sem que os municípios se preocupem em desenvolver-se economicamente de forma a garantir a sua sustentabilidade econômica, ou seja, os municípios são visceralmente dependentes desses repasses constitucionais e das transferências voluntárias de forma que traça, ao longo dos seus diversos

\footnotetext{
${ }^{4}$ Segundo José Afonso da Silva (1998, p. 7), o conceito de meio ambiente comporta quatro espécies: meio ambiente natural, meio ambiente artificial, meio ambiente cultural e meio ambiente do trabalho. O meio ambiente artificial é consubstanciado no conjunto de edificações (espaço urbano fechado) e dos equipamentos públicos, (ruas, praças, áreas verdes, espaços livres em geral: espaço urbano aberto).
}

Revista de Direito Tributário e Financeiro | e-ISSN: 2526-0138 | Salvador | v. 4 | n. 1 | p. 69 -84 | Jan/Jun. 2018 
sistemas, regulações específicas sobre essa condição urbana e estabelece, em um de seus artigos, que é preciso cumprir as funções sociais da cidade.

Para Raquel Rolnik (1995, p. 8) a cidade é uma obra coletiva que desafia a natureza. Simultaneamente com esse destaque, inaugura um modelo municipalista e descentralizador, atribuindo ao município um grande plexo de serviços, especificamente os de interesse local, tais como:

1. o de instituir e arrecadar impostos;

2. administrar o transporte coletivo;

3. garantir a educação básica e ensino fundamental;

4. acobertar atendimento à saúde;

5. suprir as necessidades em geral da população e garantir a função social da cidade.

Com o processo de urbanização intensificado, em muito pela penetração capitalista no campo, com multinacionais investindo em terras, o maior desafio do gestor na contemporaneidade é realizar os investimentos públicos necessários a fazer frente às necessidades da população em termos de saneamento básico, habitação, saúde, educação, meios de transporte, meio ambiente e outros.

Nesse contexto de grandes atribuições ao município, há que se buscar novas formas de financiamento das demandas das populações urbanas, por meio da intensificação da arrecadação de receita própria. Assim, não se trata de aumentar impostos ou taxas ou ainda contribuições, mas de aumentar a receita a partir do incremento da eficiência do aparato arrecadatório, ou ainda, pela implementação dos instrumentos de planejamento urbano já previstos, seja na própria CF/88, seja na Lei 10251/2001, seja no Plano Diretor. As ditas normas trazem os pilares sobre os quais deve ser erigido o planejamento urbano, não apenas visando à ordenação e à física do solo e seus consectários, sobretudo visando ao aproveitamento econômico máximo da cidade.

Não se trata apenas de ordenar geograficamente a cidade, mas também de preordenar a sua ocupação econômica de maneira a prover a redistribuição da sua mais valia, tornando a cidade autossustentável, assentada no binômio desenvolvimento com igual melhoria da qualidade de vida. A solução da cidade passa, pois, por gestão planejada, não apenas planejamento 
financeiro; na cidade moderna, máxime planejamento urbano. São instrumentos da política urbana:

a) Parcelamento e edificação compulsórios de área e imóveis urbanos, IPTU progressivo no tempo e desapropriação para fins de reforma urbana (art. 182, § $4^{\circ}$, da CF/88).

b) Instrumentos de regularização fundiária: usucapião especial de imóvel urbano, concessão de uso especial para fins de moradia, concessão de direito real de uso.

c) Instrumentos urbanísticos: direito de superfície, direito de preempção, outorga onerosa do direito de construir, transferência do direito de construir; operações urbanas consorciadas; estudo do impacto de vizinhança.

Todo e qualquer município brasileiro tem, segundo o Estatuto da Cidade, quatro tarefas básicas:

- Planejamento urbano, seja por meio de Plano Diretor (apenas obrigatório para cidades com mais de 20.000 - vinte mil - habitantes), seja por meio de lei de ordenação e ocupação do solo;

- Definição do perímetro urbano;

- Cadastro imobiliário;

- Cobrança de IPTU.

Obviamente que em uma cidade com o porte de Aracaju o mais ilustre instrumento de política urbana é o Plano Diretor. É nele que se condensarão as vocações da cidade, as prioridades de investimento, as definições do planejamento urbano, sendo parte integrante do processo de planejamento municipal. O art. $40, \S 1^{\circ}$, do Estatuto da Cidade é claro in verbis:

Art. 40. O plano diretor, aprovado por lei municipal, é o instrumento básico da política de desenvolvimento e expansão urbana.

$\S 1$ 1o O plano diretor é parte integrante do processo de planejamento municipal, devendo o plano plurianual, as diretrizes orçamentárias e o orçamento anual incorporar as diretrizes e as prioridades nele contidas.

$\S 2^{\text {o }}$ O plano diretor deverá englobar o território do Município como um todo.

Revista de Direito Tributário e Financeiro | e-ISSN: 2526-0138 | Salvador | v. 4 | n. 1 | p. 69 -84 | Jan/Jun. 2018 
$\S$ 3o A lei que instituir o plano diretor deverá ser revista, pelo menos, a cada dez anos.

A sua relação com a LOA, LDO e PPA ${ }^{5}$ é dialética. Não sem razão, é da sua natureza a sua renovação e reforma periódica - de 10 em 10 anos - de forma a se adequar aos constantes desafios da cidade. É por meio do Plano Diretor que o município intervém na cidade de forma a garantir o acesso de todos à mais valia urbana.

De mais a mais, os instrumentos urbanísticos previstos no Plano Diretor são também instrumentos fiscais, na medida em que a sua instrumentalização gera receita para o município e amplia as possibilidades de arrecadação com utilização, pelo menos, de:

a) Parcelamento e edificação compulsórios de área e imóveis urbanos;

b) IPTU progressivo no tempo e desapropriação para fins de reforma urbana;

c) Desapropriação com pagamentos de títulos;

d) Outorga onerosa do direito de construir;

e) Transferência do direito de construir;

f) Operações urbanas consorciadas.

Caso não haja o parcelamento/edificação/utilização compulsório, o município procederá à cobrança do IPTU progressivo no tempo, majorando a alíquota pelo prazo de 05 (cinco) anos consecutivos. Se a obrigação não se cumprir neste prazo, ou o município aguarda o cumprimento ou poderá proceder à desapropriação do imóvel, com pagamento em títulos da dívida pública.

Após a incorporação ao patrimônio, o município terá 05 (cinco) anos para aproveitá-lo ou vendê-lo. Nada obstante o seu propósito, o procedimento é moroso, o que impede a sua utilização frequente. Pressupõe o estabelecimento de coeficiente de aproveitamento básico, que é a relação que se estabelece entre a área do terreno e a área edificável. Ou seja, se em uma cidade o índice for 2 (dois), significa que para um lote de $100 \mathrm{~m}^{2}$, o proprietário só poderá construir até $200 \mathrm{~m}^{2}$, caso o proprietário deseje contratar além disso, deverá pagar à

\footnotetext{
${ }^{5}$ Lei OrÇAmentária ANuAl (LOA), Lei de Diretrizes OrÇAMENTÁRias (LDO) E Plano PluRianual (PPA).
} 
municipalidade para fazê-lo através da outorga onerosa do direito de construir, previsto no art. 28 do Estatuto da Cidade.

A receita arrecadada a partir da outorga onerosa do direito de construir será destinada às questões envolvendo a própria cidade.

Em uma cidade como Aracaju, com processo de verticalização recente, esse instrumento é de grande valia em razão da crescente especulação imobiliária e real e infeliz liberação dos índices urbanísticos preconizados pelas leis atuais e pela situação de suspensão de discussão do Plano Diretor. Consiste na autorização concedida ao proprietário do imóvel urbano, seja ele privado ou público, de transferir para outro local o direito que ele tem de construir, quando seu imóvel for considerado necessário para: a) a implantação de equipamentos urbanos e comunitários; b) preservação, quando o imóvel for considerado de interesse histórico, paisagístico, ambiental, social ou cultural; c) servir a programas de regularização fundiária, em que pese não haver transferência direta de recursos, é muito útil como substitutos às desapropriações.

O Plano Diretor consiste no conjunto de intervenções e medidas coordenadas pelo Poder Público municipal com a participação de todos, com o fim de prover transformações urbanísticas estruturais, melhorias sociais e a valorização ambiental, em uma determinada área.

É competência municipal regulamentar o instituto por meio de lei municipal específica, baseada no Plano Diretor. Na lei municipal específica, que aprova a operação urbana consorciada, constará o plano de operação com a previsão da contrapartida a ser paga pelos beneficiados pela revitalização/regularização de construções, reformas da área, assim como modificação de índices e características de parcelamento, uso, e ocupação do solo e subsolo.

Além dessa e das demais, decorrentes dos outros instrumentos, a lei específica que aprova a operação urbana consorciada pode prever a emissão pelo município de certificados de potencial adicional de construção, que serão alienados em leilão ou utilizados diretamente no pagamento das obras necessárias à própria operação.

2. O IPTU (em Aracaju e no Brasil) possui um relevante potencial distributivo não Revista de Direito Tributário e Financeiro | e-ISSN: 2526-0138 | Salvador | v. 4 | n. 1 | p. 69 -84 | Jan/Jun. 2018 


\section{utilizado e o Direito tem sua parcela de contribuição nesse contexto}

Um dos elementos que pode ser apontado como determinante para a não realização do potencial distributivo do IPTU em Aracaju, é a quase inexistência de pesquisas relacionando a política fiscal e tributária municipal com o Direito. Na medida em que “Ao passo que as outras ciências sociais desenvolveram e modificaram bastante, indo buscar na sociedade os elementos que são objeto de análise, a ciência jurídica continuou a sua elaboração teórico-dogmática, fechada em seu sistema de saberes.” (COSTA, Alexandre, 1992, p. 177), muito embora devase mencionar que esta realidade tem mudado paulatinamente nos últimos anos.

O que se busca estimular nos últimos anos é um maior interesse do próprio Direito pelo estudo empírico do fenômeno jurídico. Observa-se, desde já, que embora de forma difusa e, especialmente, na América Latina onde as desigualdades de acesso à justiça são evidentes, professores e pesquisadores do campo do Direito começam a dedicar-se à realização de pesquisas empíricas com o objetivo principal de observar a efetividade da lei, a eficácia das instituições jurídicas e a garantia de respeito aos direitos de todos os cidadãos (IGREJA, 2017, p. 14).

Desta maneira, serão lembradas algumas pesquisas com dados que guardem relação com o tema aqui discutido. Isto será feito na tentativa de estabelecer relações entre estes trabalhos e a coleta de dados que foi realizada a respeito do IPTU de Aracaju, para que a análise sobre os aspectos distributivos do IPTU não fique restrita e seja possível compreendê-la em um espectro mais amplo.

Uma pesquisa que acrescenta bastante ao trabalho de coleta de dados realizado no município de Aracaju é a de Pedro Humberto Bruno de Carvalho Jr. (2009) ${ }^{6}$, que visa verificar a distribuição do patrimônio imobiliário das famílias brasileiras e a sua principal forma de tributação, o Imposto Predial e Territorial Urbano (IPTU). Parte-se da hipótese central de que:

o usufruto do patrimônio imobiliário das famílias é mais concentrado que a própria renda familiar, não obstante o IPTU apresentar comportamento dúbio do ponto de vista distributivo. A carga tributária é maior sobre as famílias mais ricas, já que poucas famílias pobres de fato pagam o imposto. Porém, quando se analisa somente o universo de pagantes, a sua estrutura é altamente regressiva, com os contribuintes mais pobres sofrendo uma tributação maior (CARVALHO JR, 2009, p. 5).

\footnotetext{
6 Técnico de Planejamento e Pesquisa da Diretoria de Estudos Regionais e Urbanos - Dirur/Ipea.
} 
O autor coloca como possíveis causas da estrutura altamente regressiva do IPTU

A má gestão administrativa, a defasagem e regressividade nas avaliações imobiliárias oficiais em relação aos valores de mercado e a falta de abrangência do cadastro imobiliário fiscal entre os domicílios mais pobres (...) Também é mostrado que uma ampla política de isenção de IPTU aliada à má qualidade administrativa e avaliatória acabam isentando famílias de renda média e alta do pagamento desse imposto" (CARVALHO JR., 2009, p. 5).

O campo de trabalho pesquisado por Carvalho (2009) foram 365 municípios, todos acima de 50.000 habitantes.

Através de resultados que, em muito, se assemelham aos da pesquisa aqui apresentada, o autor chega à conclusão que, em cidades com maior número de contribuintes, a regressividade do IPTU pode ser vista de maneira mais nítida, e o aumento do imposto (sem a aplicação concomitante de alíquotas progressivas, ou do enfrentamento do problema da regressividade das avaliações dos imóveis), acaba por agravar a desigualdade na cobrança deste tributo, consequentemente

aumentando ainda mais a antipatia do contribuinte e a pressão política contra o imposto, muito embora o grupo de proprietários de imóveis mais valorados tenha maior poder de organização e costume realizar pressões políticas e judiciais contra o aumento da tributação de suas propriedades, impedindo a aplicação de grandes mudanças que passaram a ser permitidas pelas ECs e o Estatuto das Cidades (CARVALHO JR., 2009, p. 27).

Uma vez que o número de pagantes pode ser influenciado por fatores como os critérios utilizados para conceder isenções, o trabalho de pesquisa mostra que os municípios devem optar por critérios de isenção que tenham mais controle, como por exemplo, localização e valor venal. A pesquisa também mostrou que o IPTU apresenta uma certa cultura de inadimplência, ocasionada muitas vezes pela ineficiência na arrecadação e na cobrança judicial, problema este localizado também no município de Aracaju ${ }^{7}$, inclusive convivendo com casos de fraude na

\footnotetext{
${ }^{7}$ A “Operação Venal” tratou de fraudes na arrecadação do IPTU em Aracaju e foi noticiada por toda a imprensa local. A estimativa é que mais de R\$ 17.000.000,00 (dezessete milhões de reais) deixaram de ser arrecadados pelos órgãos da Fazenda Municipal decorrentes da fraude. 17 pessoas participaram do esquema, incluindo empresários e funcionários da prefeitura.
}

Revista de Direito Tributário e Financeiro | e-ISSN: 2526-0138 | Salvador | v. 4 | n. 1 | p. $69-84$ | Jan/Jun. 2018 
cobrança do referido tributo ${ }^{8}$. Daí resulta o caráter não distributivo verificado na confirmação das hipóteses aventadas.

Através deste estudo pode-se confirmar o enorme potencial distributivo não utilizado pelas administrações municipais com relação ao IPTU, sendo identificados os mecanismos de progressividade extrafiscal e fiscal que vem a ser praticamente ignorados nas grandes cidades.

O papel do IPTU na atualidade, ou seja, a não distributividade histórica das políticas fiscais municipais, é perpetuada mesmo após a Constituição de 88 e o Estatuto das Cidades, que, pelo menos em tese, deveriam ter feito do IPTU um tributo indutor do crescimento ordenado das cidades e de enfrentamento das concentrações imobilizadas de renda. Isto pode ser bem exemplificado com o número de municípios que possuíam alíquotas progressivas no ano em que a pesquisa mencionada foi realizada,

Carvalho Jr. (2008) analisou a estrutura de alíquotas de 365 municípios (todos acima de 50 mil habitantes) no ano de 2007 e encontrou que apenas 14\% desses municípios tinham alíquotas progressivas de IPTU (isto é, aumentavam conforme o valor venal do imóvel). Já em 6,8\% deles, as alíquotas variavam conforme localização do imóvel e em 5,5\% conforme tamanho do imóvel. Além disso, 26,9\% desses municípios previam a possibilidade do 'IPTU Progressivo no venal' para terrenos vagos. Com isso, pode-se dizer que cerca de um quarto das cidades brasileiras acima de 50 mil habitantes possui alíquotas progressivas ou seletivas, de acordo com o artigo 156 da CF de 1988 (CARVALHO JR. 2008 apud CARVALHO JR., 2009, p. 10).

Embora o texto constitucional seja no sentido de exigir que o IPTU induza o cumprimento da função social da propriedade e seja cobrado em respeito à capacidade contributiva, tudo isso através das progressividades no tempo e de acordo com o valor venal, a opção da grande maioria das cidades pesquisadas tem sido em descumprir o texto constitucional cotidianamente, distinguindo em muito a cobrança real do dever ser constitucional, revelando um dos aspectos que interditam a efetivação dos aspectos distributivos que o IPTU possui.

Outra pesquisa que apresenta semelhanças, quanto ao objeto da que foi aqui apresentada, é a também realizada por Pedro Humberto Bruno de Carvalho Júnior (2012) com relação à defasagem do IPTU no município do Rio de Janeiro. Com base numa amostra de

\footnotetext{
${ }^{8}$ JUIZ concede prisão domiciliar a um dos presos pela 'Operação Venal': Empresário é o terceiro que consegue o benefício. Portal TVSERGIPE. Disponível em: <http://g1.globo.com/se/sergipe/noticia/2016/12/juiz-concedeprisao-domiciliar-um-dos-presos-pela-operacao-venal.html>. Acesso em: 29 de junho, 2018.
}

Revista de Direito Tributário e Financeiro | e-ISSN: 2526-0138 | Salvador | v. 4 | n. 1 | p. $69-84$ | Jan/Jun. 2018 
8.408 imóveis avaliados pela Caixa Econômica Federal entre 2006 e 2009, o autor comparou os valores avaliados com os valores venais, bem como com o montante tributado pelo IPTU em cada unidade.

O autor assevera que o IPTU está em nível muito abaixo do potencial arrecadatório. Além disso, afirma que o IPTU tem um papel fundamental no enfrentamento da desigualdade espacial, que "pode e deve ser diminuída através de uma tributação imobiliária eficaz e progressiva e através do gasto público focalizado, principalmente como forma de repartir para a sociedade os ganhos imobiliários individuais, numa política que possibilite recursos para o melhor desenvolvimento econômico e social” (CARVALHO JR., 2012, p. 12). A matriz tributária brasileira baseia-se essencialmente nos impostos indiretos sem absorver adequadamente o texto constitucional de 1988 no que diz respeito à propulsão de mudanças, se opondo a um modelo redistributivo de tributação. O Direito Tributário, em consequência da Reforma Tributária inaugurada pelo texto constitucional de 1988, deve transforma-se radicalmente, inclusive ultrapassando as normas fixadas nos textos, exigindo uma interdisciplinaridade para que possam ser absorvidos os mecanismos de distributividade já existentes e também que possam ser elaborados novos mecanismos distributivos a surgir. $\mathrm{O}$ IPTU deve, como consequência, finalmente adaptar-se à nova realidade constitucional surgida a partir de 1988.

Na interpretação dos dados a respeito da defasagem do IPTU o autor chega às seguintes conclusões na verificação das hipóteses levantadas: 1) o IPTU tem fundamental função extrafiscal, podendo induzir o aproveitamento da terra e a efetivação da função social da propriedade; 2) a aferição do correto valor de mercado dos imóveis é condição fundamental para que a cobrança do IPTU seja equânime; 3) a relação entre arrecadação com impostos imobiliários e PIB é muito baixa no Brasil, mesmo em comparação com países em desenvolvimento como Argentina, Colômbia e África do Sul; 4) a concessão de isenções e incentivos fiscais nas principais capitais do Brasil é bastante abrangente, tendo relação direta com o baixo número de contribuintes do IPTU; 5) com relação aos imóveis localizados no Estado do Rio de Janeiro, foi observada uma grande defasagem entre os valores venais fixados

Revista de Direito Tributário e Financeiro | e-ISSN: 2526-0138 | Salvador | v. 4 | n. 1 | p. 69-84 | Jan/Jun. 2018 
e os valores avaliados pela CAIXA; 6) foi observada também uma grande regressividade horizontal na tributação dos imóveis no Estado do Rio de Janeiro (CARVALHO JR., 2012). Diante de tais resultados, o autor afirma que "O município deveria partir para outra linha, aplicando o IPTU progressivo no Tempo, previsto na CF de 1988 e regulamentado pelo Estatuto das Cidades, e abolindo o amplo desconto no IPTU oferecido aos proprietários dos terrenos, além de avaliar o valor da terra a preços condizentes com os do mercado” (CARVALHO JR., 2012, p. 85).

O autor chega a firmar que:

O presente estudo sobre o município do Rio de Janeiro apresentou vários motivos que ocasionam a baixa arrecadação na cidade: avaliações defasadas, elevada concessão de isenções e reduções tributárias, inequidade horizontal, além da falta de compromisso do IPTU como instrumento de política urbana. Além da necessidade de reforma do IPTU carioca, seria relevante a elaboração de estudos empíricos semelhantes em outras cidades, que poderiam ser feitos através do uso das avaliações imobiliárias individuais pela CAIXA em todo o país. Fortaleza, Salvador, Brasília, Manaus, Belém e Porto Alegre são exemplos de grandes cidades brasileiras com indicadores de IPTU abaixo das expectativas e que necessitam reformar os seus sistemas de avaliação imobiliária. O atual e esperado contínuo crescimento econômico brasileiro levará sem dúvida ao incremento do valor dos imóveis e os municípios devem estar preparados para esta nova realidade, não deixando que os valores oficiais fiquem cada vez mais distantes dos de mercado. O quase monopólio da CAIXA na concessão de crédito imobiliário residencial no Brasil a torna um importante agente no auxílio aos municípios nos trabalhos de atualização das PGVs, com a informação de suas avaliações imobiliárias em grandes cidades. (CARVALHO JR, 2012, p. 85).

Vale ressaltar que existem outras pesquisas, poucas é verdade, que tiveram por objeto de estudo os aspectos distributivos do IPTU, e desta maneira complementaram o trabalho aqui realizado. A pesquisa de Marcos Barbosa Vasques (2009) que também tomou como base o município do Rio de Janeiro, e a de José Roberto R. Afonso, Erika Amorim Araújo e Marcos Antônio Rios da Nóbrega (2013), realizando um diagnóstico abrangente do IPTU no Brasil, são exemplares desta contribuição.

Preocupados mais com o potencial distributivo não utilizado pelo IPTU nas principais cidades brasileiras, estes autores chegam a conclusões que reforçam as hipóteses aqui apresentadas. Os autores mencionados deixam claro em suas pesquisas, os aspectos distributivos atrofiados do IPTU, ao detectar os mecanismos de progressividade não utilizados a contento, tanto os fiscais quanto os extrafiscais.

Revista de Direito Tributário e Financeiro | e-ISSN: 2526-0138 | Salvador | v. 4 | n. 1 | p. 69 -84 | Jan/Jun. 2018 
Dos trabalhos apresentados, pode-se traçar um paralelo com a coleta de dados realizada no município de Aracaju e buscar estabelecer uma avaliação dos aspectos distributivos do IPTU que sirva para uma análise mais abrangente. Estes trabalhos compreendem o esforço de pesquisadores e pesquisadoras em esmiuçar os aspectos distributivos do IPTU no Brasil, cada qual com o aporte teórico que mais se adequou a sua pesquisa, e, embora não tratem o tema da mesma maneira, pode-se afirmar que as conclusões de cada trabalho são complementares, e não excludentes ou colidentes. A diferenciação geográfica da delimitação das pesquisas permite que o quadro a ser traçado tenha a abrangência do IPTU em todo Brasil, pois somados a coleta de dados realizada em Aracaju estão pesquisas feitas em 365 municípios com mais de 50 mil habitantes espalhados por todas as regiões do Brasil; nas 12 principais capitais do país; e no Rio de Janeiro, segunda maior cidade do país.

\section{Considerações finais: Traçando um perfil básico do IPTU no Brasil}

Uma vez feito o percurso geral pela investigação selecionada, acredita-se que seja possível unir os principais elementos das diferentes pesquisas mencionadas para traçar um perfil básico do IPTU no Brasil.

O ISS e o IPTU são as principais fontes de arrecadação para o conjunto das prefeituras brasileiras. O IPTU é um imposto com alta visibilidade, sendo que os contribuintes costumam pressionar o poder público, no sentido de minimizar suas obrigações com tal exação. As atualizações periódicas das Plantas Genéricas de Valores são fundamentais, mas demandam grande mobilização de recursos administrativos, além de dependerem de aprovação da Câmara de Vereadores, o que termina por politizar a questão. A utilização dos mecanismos de progressividade do IPTU é relativamente recente no país, o que faz com que o tema ainda não tenha sido objeto de minuciosa análise doutrinária e jurisprudencial, prejudicando assim o potencial arrecadatório e distributivo do IPTU. Por fim, se faz necessário melhor investigar os critérios utilizados para a concessão de isenções e de anistia, principalmente no que diz respeito ao cumprimento da Lei de Responsabilidade Fiscal.

Revista de Direito Tributário e Financeiro | e-ISSN: 2526-0138 | Salvador | v. 4 | n. 1 | p. 69 -84 | Jan/Jun. 2018 
Em síntese, revela a (des)funcionalidade dos mecanismos distributivos do IPTU, desvendando por conseguinte a ineficácia do texto constitucional no que diz respeito ao sistema tributário. Contraditoriamente, o legislativo enfrentou muitos dos problemas pertinentes à regulamentação dos dispositivos constitucionais que tratam dos mecanismos distributivos do IPTU, mas posiciona-se de maneira conformista e aceita passivamente a realidade não distributiva atual do IPTU. O legislativo conseguiu detectar as falhas e incompletudes do texto constitucional relacionado ao IPTU, enfrentando-as com a EC 29/2000 e o Estatuto das Cidades chegou a idealizar o IPTU como um instrumento importante para a indução do cumprimento da função social da propriedade e de enfrentamento à concentração de renda imobilizada, mas pouco, ou nada, tem feito no sentido de cobrar a implementação de tais regulamentações do texto constitucional por parte dos executivos municipais.

Diante deste perfil do IPTU, pode-se afirmar que o exercício do que aqui se chamou de aspectos distributivos deste imposto não estão sendo assegurados. Portador de mecanismos de progressividade fiscal e extrafiscal, a cobrança do IPTU na prática reproduz formas já típicas da matriz tributária brasileira, diga-se de passagem excessivamente regressiva: isenções concedidas sem a observância das necessárias condicionantes, alíquotas que não conseguem enfrentar o problema dos vazios urbanos, valores venais em dissonância com os reais valores de mercado, etc.

O IPTU, após ter seus mecanismos de progressividade devidamente regulamentados, insere-se no contexto de regressividade da matriz tributária brasileira. Embora não seja objetivo deste trabalho aprofundar nessa análise, pode-se afirmar que a não realização dos aspectos distributivos do IPTU através dos mecanismos de progressividade contidos no texto constitucional de 1988 é reforçado e adaptado à regressiva matriz tributária brasileira, de forma que resta interditada sua distributividade pelo legislativo, executivo e judiciário. Uma vez que os poderes constituídos normalmente defendem interesses de uma determinada parcela da sociedade, e, não necessariamente, seguem à risca o texto constitucional, fecha-se a oportunidade de que a distributividade seja realizada plenamente através da tributação.

Com os elementos que foram aqui expostos, somados às pesquisas dos outros autores, pode-se traçar um perfil básico do IPTU no Brasil. Após o estabelecimento deste perfil básico, e sendo predominantemente não distributivo e regressivo, pode-se depreender que os aspectos 
distributivos do IPTU não são relevantes, pelo menos no que diz respeito à sua concretização. Esta regressividade da matriz tributária brasileira reproduz um senso comum sobre o Direito Tributário.

Como foi dito anteriormente, não é objeto da análise em questão, o processo de inserção do IPTU no contexto da regressividade da matriz tributária brasileira, porém os ditames da política fiscal nacional determinam antecipadamente quais tributos exercerão esta ou aquela função distributiva.

\section{Referências}

AFONSO, José Roberto; ARAÚJO, Erika; NÓBREGA, Marcos Antônio. IPTU no Brasil um diagnóstico abrangente. Rio de Janeiro: FGV Projetos, v. 4, 2013.

BRASIL. Constituição Federal de 1988. Promulgada em 5 de outubro de 1988.

CARVALHO JR., Pedro Humberto Bruno. Aspectos distributivos do IPTU e do patrimônio imobiliário das famílias brasileiras. Rio de Janeiro: IPEA, 2009.

Defasagem do IPTU no município do Rio de Janeiro: uma proposta de reforma. Rio de Janeiro: IPEA, 2012.

COSTA, Ana Maria. Espaço físico urbano e participação social: a importância da compreensão dos conceitos. Revista de Direito da Cidade, Rio de Janeiro, v. 06, n. 01, p. 168-179, 2014.

COSTA, Alexandre Bernardino. Ensino jurídico: disciplina e violência simbólica. Dissertação (Mestrado em Ciências Humanas com especialidade em Direito), Universidade Federal de Santa Catarina, Florianópolis, 1992.

COUTINHO, Ronaldo. A mitologia da cidade sustentável no capitalismo. In: . E Bonizzatto, Luigi (Org.) Direito da cidade: novas concepções sobre as relações jurídicas no espaço social urbano. Rio de Janeiro: Lumen Juris, 2007. 
DAUD, Samira dos Santos. O direito à moradia adequada: através dos instrumentos urbanísticos de regularização fundiária, a partir da lei n. 11977/2009. São Paulo: Max Limonad, 2015.

HARVEY, David. A produção capitalista do espaço. São Paulo: Annablume, 2005.

IGREJA, Rebecca Lemos. O Direito como objeto de estudo empírico: o uso de métodos qualitativos no âmbito da pesquisa empírica em Direito. In: Machado, Maíra Rocha (Org.). Pesquisar empiricamente o direito. São Paulo: Rede de Estudos Empíricos em Direito, 2017.

MOREIRA, Danielle de Andrade. O direito a cidades sustentáveis. Revista de Direito da Cidade. Rio de Janeiro, v. 06, n. 02, p. 179-200, 2006.

ROLNIK, Raquel. O que é cidade. São Paulo: Brasiliense, 1995.

SANTOS, Milton. A urbanização brasileira. 5. ed. 3. Reimp. São Paulo: USP, 2013.

SILVA, José Afonso da. Direito ambiental constitucional. 2. ed. São Paulo: Malheiros, 1998.

VASQUES, Marcos. IPTU teoria geral do garantismo: o controle de constitucionalidade de suas leis após a EC 29/2000. Curitiba: Juruá, 2009.

VEIGA, José Eli da. Nem tudo é urbano. Ciência e Cultura. [online] São Paulo, v. 56, n. 02, p. 26-29, 2004. 